
\title{
25 Research Square \\ Psychometric properties of the Tilburg Pregnancy Distress Scale-Persian version (TPDS-P)
}

\section{Solmaz Pishahang}

Research Center of Psychiatry and Behavioral Sciences, Tabriz University of Medical Sciences, Tabriz

\section{Sevil Hakimi}

School of Nursing and Midwifery, Tabriz University of Medical Sciences

\section{Solmaz Vatankhah}

Research Center of Psychiatry and Behavioral Sciences, Tabriz University of Medical Sciences, Tabriz

\section{Saeideh Ghaffarifar}

Medical Education Research Center, Health Management and Safety Promotion Research Institute,

Tabriz University of Medical Sciences

Fatemeh Ranjbar ( $\nabla$ fk_ranjbar@yahoo.com )

Research Center of Psychiatry and Behavioral Sciences, Tabriz University of Medical Sciences, Tabriz

\section{Research Article}

Keywords: Tilburg Pregnancy Distress Scale, Pregnant Women, Psychometric Properties

Posted Date: December 23rd, 2020

DOl: https://doi.org/10.21203/rs.3.rs-113706/v1

License: (c) (i) This work is licensed under a Creative Commons Attribution 4.0 International License.

Read Full License 


\section{Abstract}

Background Given the importance of screening pregnant women's distress, it was intended to investigate the psychometric properties of the Persian version of the Tilburg Pregnancy Distress Scale (TPDS-P) for screening pregnancy distress.

Methods This methodological study was conducted with participation of 360 pregnant women. The TPDS was translated into Persian. Factor analysis was used to investigate the construct validity. The results of the correlation test between the two questionnaires DASS-21 and TPDS-P were used to determine the criterion validity. Internal consistency of the items was calculated by the Cronbach's alpha coefficient. Stability of the results was examined by test-retest method. To examine the structure of the factors derived from exploratory factor analysis, fitness of the model was done through confirmatory factor analysis. Statistical analysis was done using SPSS software.

Results KMO outcomes were $0.846(p=0.001)$. 16 items of TPDS-P accounted for 51.42 percent variances. The TPDS-P exhibited appropriate fitness. There was poor to moderate but significant direct correlation between the subscales of DASS-21 and TPDS-P. Cronbach's alpha coefficient of the TPDS-P was 0.81 .ICC was 0.81 .

Conclusion TPDS-P can be used as a scale with appropriate validity and reliability in Farsi-speaking societies to evaluate women's distress during pregnancy.

\section{Background}

Pregnancy and delivery are physiological events in a woman's life that, due to changes in physical conditions, family and workplace roles, and sometimes feelings and attitudes toward motherhood; require bio psychosocial adjustment in the pregnant woman and her family (1). Pregnancy-specific distresses mean the mother's fears and concerns about the health of the fetus, parent relationships, relationship with the spouse and others, changes in the body, delivery and pregnancy, and the baby's health (1). Recent investigations have shown that more than $80 \%$ of pregnant women experience some degrees of psychosocial stress, and $20 \%$ of women experience severe stress (2). Researches over the past two decades have shown a relationship between maternal psychological distress in the prenatal period and the poor delivery, fetal and neonatal consequences (3). Pregnancy distress has been shown to cause changes in fetal heart rate, low Apgar score, breastfeeding problems, fetal deaths, low birth weight, late attachment to parents, preeclampsia, placental abnormalities, preterm birth, fetal distress and emergent cesarean section (1).

Depression and anxiety are closely related (4). In general, stress, depression, or anxiety during pregnancy not only have a major impact on women's health and quality of life, and increase the risk of midwifery complications, but also may affect the child's neurological and emotional development (5) and ultimately predict his or her illness and health problems (6); therefore, there is a need to measure psychological functioning during pregnancy and screen these vulnerable women in an effective way. There are few 
specific instruments to assess women's distress during pregnancy (5). Studies have shown that only $20 \%$ of gynecologists routinely screen for anxiety disorders in their clinical work (7) and less than half of them state that they have received sufficient training to diagnose depression during their residency (8).

To measure depression, anxiety and stress in the general population, various instruments such as Depression Anxiety Stress scales-21 (DASS-21) are used by researchers. In a study conducted by Asghari et al. in Iran in 2008, the Persian version of the DASS-21 was confirmed in terms of validity and reliability of all three subscales and based on the results of that study; the Persian version of DASS-21 has the necessary conditions to be used in the adult Iranian population and in psychological researches (9). To determine the level of distress during pregnancy, Victor JM Pop et al. in the Netherlands in 2011 presented a valid scale for examining the specific psychological function of pregnancy named Tilburg Pregnancy Distress Scale (TPDS), which included 22 initial items in the questionnaire then their psychometric properties were investigated using exploratory factor analysis. This resulted in a 17-item TPDS, which was further explored by confirmatory factor analysis and concurrent validity assessment and finally a 16-item scale was developed. Subsequent analysis confirmed that this scale has two subscales of negative affect and partner involvement and it can be a valid and useful instrument for the assessment of pregnancy distress (5). Although some of the issues that affect pregnancy distress are among common worldwide problems, a number of factors related to different cultures can also be involved. To determine if this scale (TPDS) can be useful for pregnant women in Iran, this study aimed to investigate the psychometric properties (validity and reliability) of the Persian version of the Tilburg Pregnancy Distress Scale (TPDS-P) for screening the pregnancy distress.

\section{Methods}

\section{Type of study}

This is a methodological study in terms of nature and descriptive cross-sectional in terms of implementation method.

\section{Population, sample size, and sampling method}

The population of the present research includes pregnant women, under the coverage of the routine pregnancy care provided by healthcare centers in Tabriz, Iran, who were pregnant at the time of sampling (October 2017 to March 2018).

Since an exploratory factor analysis was made, sample size was assumed to be 160 with 5-10 women considered for each of the 16 items. Then, final sample size was calculated to be 360 , given the sample including 200 pregnant women required for the confirmatory factor analysis (10). The multistage random sampling method was used in the research. After 15 centers were randomly selected from the list of all healthcare centers in Tabriz using the www.random.org website, the files of the pregnant women at the time of sampling were examined, then a number of files were selected from each center (using quota random sampling) regarding to the total number of available files using the mentioned website. After 
giving detailed explanations about the reasons, purposes and methods of the research, the pregnant women were invited to the medical centers via phone call to participate in the study. If agreed, they would be requested to attend the treatment $\&$ health centers according to the specified schedules. In that step, they were given comprehensive information about the methods and benefits of the research and the confidentiality of their information. If they agreed to participate in the study, they were reevaluated in terms of the inclusion criteria. If they were eligible, written informed consent for participation would be obtained from them. The inclusion criteria of the study included: age above 18 years, gestational age above 24 weeks, absence of a chronic disease, absence of high-risk pregnancy (including gestational diabetes or preeclampsia), absence of twin pregnancy, absence of assisted reproductive techniques for pregnancy, and voluntary participation. The exclusion criteria of the study included presence of any intellectual or cognitive problems.

\section{Information collection instruments and methods}

All the participants completed three questionnaires including a demographic questionnaire, TPDS-P and DASS-21 (used for investigation of the criterion validity of TPDS-P), each one described below:

1) Demographic questionnaire: This contained questions on age, marital status, occupation, level of education, and economic status of the participants.

2) TPDS: The original TPDS is composed of two major subscales and a total of 16 items. The first, negative affect subscale contains 12 items regarding the woman's fear, anxiety, and concerns about pregnancy and postpartum period, and the second partner involvement subscale, contains 4 items regarding her partner's support during pregnancy. For each of the items, the participants would select one of four alternatives based on their feelings and perceptions of their pregnancies, depending on the severity of their experiences, leading to scores from 0 to 3 assigned to the answers, ultimately ( 0 for very often, 1 for fairly often, 2 for now and then, and 3 for rarely or never). In the calculation of the final scores, the scores for items $3,5,6,7,9,10,11,12,13,14$, and 16 were considered in reverse. The minimum score is 0 , and the maximum is 48 . Overall, a higher score indicates greater distress. The maximum score for the negative affect subscale is 36 , and that for the partner involvement subscale is 12 (1). The cutoff of a high score on the TPDS and its subscales (= distressed woman), was set at the $90^{\text {th }}$ percentile which resulted in the following cutoff scores: for the overall scale $>17$, for its subscale ' $N A$ ' $>12$, and for its subscale 'Pl' >7 (5).

The authors of the research obtained permission for the translation of the original scale into Persian and its adaptation and application. The process of translation and adaptation has gone through using the forward-backward translation approach: Two bilingual translators, including a psychiatrist and a reproductive healthcare specialist, separately translated the original version of the scale into Persian. The two translated versions were compared for the identification of any disagreements and ambiguities. After the points of disagreement were revealed, and a single version was provided, the agreed-on version was translated into English by two native translators with no involvement in the process of investigation. 
Finally, a committee composed of the translators, first author, and the corresponding author compared the new English version of the scale to the original one and eliminated meaning related problems.

3) DASS: This is an instrument that provides valid and reliable assessments of three constructs: depression, anxiety, and stress (11). Both the internal consistency and concurrent validity of DASS and DASS-21 are in an acceptable to excellent range. Furthermore, the 21 -item version has several advantages over the full 42-item one, and can therefore be preferred (4). The original DASS-21, with a total of 21 items, is composed of three subscales: depression, anxiety, and stress. Each subscale contains 7 items, addressing one's conditions over the previous week. A score from 0 to 3 is assigned to each item (3 for Applied to me very much, 2 for Applied to me to a considerable degree, 1 for Applied to me to some degree, and 0 for did not apply to me at all). The score for each subscale can range from 0 to 21 . The higher the score, the more severe the depression, anxiety, and stress $(9,12)$. Since this is the shortened form of the main 42-item scale, the final score for each subscale needs to be multiplied by 2 . Then, the categorization in Table 1 can be referred for specification of the severity of the symptoms and interpretation of the scores.

\section{Table 1. Interpretation of DASS scores with respect to the defined cutoff}

\begin{tabular}{|llll|}
\hline Severity & Depression & Anxiety & Stress \\
\hline Normal & $0-9$ & $0-7$ & $0-14$ \\
\hline Mild & $10-13$ & $8-9$ & $15-18$ \\
\hline Moderate & $14-20$ & $10-14$ & $19-25$ \\
\hline Severe & $21-27$ & $15-19$ & $26-33$ \\
\hline Extremely severe & 28 and above & 20 and above & 33 and above \\
\hline
\end{tabular}

This version has been translated into Persian by Asghari et al. in 2008, and has exhibited proper psychometric properties (good to excellent) in the Iranian population $(9,11)$

\section{Statistical analysis}

The factor analysis method with SPSS was used for the investigation of construct validity, and the results of the correlation test between the DASS-21 and TPDS-P were used for investigation of the criterion validity.

For the investigation of reliability, internal consistency of the items was examined. For the measurement of internal consistency, the Cronbach's alpha coefficient was calculated. For the measurement of stability of the results, the test-retest method was used, and intra class correlation coefficient (ICC) was 
calculated. For that purpose, the questionnaire was redistributed to 30 of the participants after 15 days, and correlation coefficient was examined through the ICC test using SPSS. Values above 0.7 were considered acceptable (13).

The KMO test was used for the examination of sample size adequacy, and the Bartlett's test of sphericity was used for the identification of suitability of the data for factor analysis. Factor rotation was carried out through varimax rotation. Minimum factor load was considered to be 0.3 . Eigenvalues on the Scree plot were interpreted for the specification of the number of factors. The naming of the items was done by considering the original questionnaire and the justification of the naming.

After the exploratory factor analysis was completed, the fitness of the exploratory model was assessed through confirmatory factor analysis. The fit indices were used for the examination of the model fitness. The intended indices and their acceptable values for confirmation of the model are as follows: Chisquare statistic (Bollen, 1989) $p<0.05$, Root mean square error of approximation (RMSEA) $<0.08$, Comparative fit index (CFI) (Goffin, 1993) > 0.9, Normal fit index (NFI) (Bentler and Bonett, 1980) >0.9, Tucker-Lewis index (TLI or NNFI) (Tucker and Lewis, 1998) >0.9, Incremental fit index (IFI) (Bollen, 1989) $>0.9$.

\section{Ethical considerations}

Before the research began, official permission was obtained from the author of the original version of TPDS, Victor J. M. Pop. Conducting this study was approved by Tabriz University of Medical Sciences (TUoMS) ethical committee. The ethical code was IR.TBZMED.REC.1396.70. All methods were performed in accordance with the relevant guidelines and regulations at TUoMS. Participation in the study was optional and it was done after obtaining written informed consent. Informed consent was obtained from husbands for illiterate women. It was possible for the participants to leave the study whenever they wanted. Before the study was conducted, the purposes of the research were explained to the participants. The information of the participants and their families were kept confidential.

\section{Results}

\section{Demographic characteristics of the participants}

In this study, 360 pregnant women were investigated. The results of the study of demographic characteristics of the participants are shown in the Table 2.

\section{Table 2. Demographic characteristics of the participants of the study}




\begin{tabular}{|c|c|c|}
\hline Variable & Frequency & Frequency percentage \\
\hline Age* $^{*}$ & 28.26 & 5.95 \\
\hline \multicolumn{3}{|l|}{ Number of pregnancies } \\
\hline First pregnancy & 139 & 38.6 \\
\hline Second pregnancy & 146 & 40.6 \\
\hline Third pregnancy or more & 75 & 20.9 \\
\hline \multicolumn{3}{|l|}{ Number of childbirths } \\
\hline First childbirth & 152 & 42.2 \\
\hline Second childbirth & 156 & 43.3 \\
\hline Third or more childbirth & 52 & 14.5 \\
\hline \multicolumn{3}{|l|}{ Marital status } \\
\hline Married & 358 & 99.4 \\
\hline Single & 0 & 0 \\
\hline Widowed & 1 & 0.3 \\
\hline Divorced & 1 & 0.3 \\
\hline \multicolumn{3}{|l|}{ Occupation } \\
\hline Housewife & 281 & 78.1 \\
\hline Government job & 27 & 7.5 \\
\hline Freelance job & 33 & 9.2 \\
\hline Retired & 0 & 0 \\
\hline Self employed & 19 & 5.3 \\
\hline \multicolumn{3}{|l|}{ Education level } \\
\hline Illiterate & 4 & 1.1 \\
\hline Primary/Secondary School & 88 & 24.4 \\
\hline High School/Diploma & 202 & 56.1 \\
\hline University degree & 66 & 18.3 \\
\hline \multicolumn{3}{|l|}{ Spouse occupation } \\
\hline Government job & 91 & 25.3 \\
\hline
\end{tabular}




\begin{tabular}{|lll|}
\hline Freelance job & 262 & 72.8 \\
\hline Retired & 1 & 0.3 \\
\hline Not employed & 6 & 1.7 \\
\hline Spouse education level & & \\
\hline Illiterate & 5 & 1.4 \\
\hline Primary/Secondary School & 84 & 23.3 \\
\hline High School/Diploma & 185 & 51.4 \\
\hline University degree & 86 & 23.9 \\
\hline Home Status & & \\
\hline Homeowner & 134 & 37.2 \\
\hline Tenant & 166 & 46.1 \\
\hline Living with parents or relatives & 60 & 16.7 \\
\hline Monthly income status to meet your needs & & \\
\hline I am completely in financial well-being & 19 & 5.3 \\
\hline I am living with economizing the budget & 120 & 33.3 \\
\hline I sometimes have financial difficulties & 140 & 38.9 \\
\hline I always have financial difficulties & 70 & 19.4 \\
\hline I am in complete poverty & 10 & 2.8 \\
\hline *Expresses the mean (+/- standard deviation) & & \\
\hline
\end{tabular}

\section{Data analysis}

\section{Exploratory factor analysis}

In this study, the KMO value was 0.846 and the Bartlett's test of sphericity was conducted to specify whether the obtained correlation matrix was significantly different from zero, which would justify application of factor analysis, and it was observed that $p<0.001$ (Chi-square $=2468$ and Degree of freedom $=120$ ).

The rate of the common consequences in preliminary 16 items was more than 0.5 in all cases. 
16 items with eigenvalues greater than 1 were extracted. They accounted for a total of 51.42 percent of all the variances for the two factors. Considering the explanation of 50 percent of the variances by the factors, and using logical interpretability and the result of the scree plot (Figure 1), and most importantly by considering the original questionnaire, 2 factors were found to be appropriate. Then agreements were made on the naming of each factor based on the original questionnaire.

The 2 factors were described based on the original questionnaire. The first factor, negative affect, with 11 items accounted for a variance of $30.31 \%$. The second factor, partner involvement, with 5 items explained a variance of $21.1 \%$.

Table 3 shows the factor loading values of the items in each subscale.

Table 3. Factor loading values of the items in each subscale of the TPDS-P

\begin{tabular}{|llllll|}
\hline No. & Expressions & \multicolumn{3}{l}{ Factor loading } & \\
\cline { 3 - 6 } & & $\mathbf{1}$ & $\mathbf{2}$ & $\mathbf{3}$ & $\mathbf{4}$ \\
\hline 1 & I am enjoying my pregnancy & 0.024 & 0.781 & 0.270 \\
\hline 2 & My partner and I are enjoying the pregnancy together & 0.029 & 0.849 & 0.121 \\
\hline 3 & I worry about my pregnancy & 0.768 & & \\
\hline 4 & $\begin{array}{l}\text { The pregnancy has brought my partner and me closer } \\
\text { together }\end{array}$ & & 0.823 & 0.005 \\
\hline 5 & I worry about the delivery & 0.823 & & & \\
\hline 6 & I worry about the health of my baby & 0.781 & 0.029 & \\
\hline 7 & I worry about my job once the baby is born & 0.122 & 0.062 & 0.398 & 0.137 \\
\hline 8 & I feel supported by my partner & 0.111 & 0.783 & & \\
\hline 9 & I worry about our financial status after childbirth & 0.375 & 0.124 & 0.263 & 0.645 \\
\hline 10 & I am afraid I will lose self-control during delivery & 0.758 & & & 0.183 \\
\hline 11 & I often worry about choices concerning the delivery & 0.738 & & & 0.141 \\
\hline 12 & The delivery is troubling me & 0.672 & 0.187 & 0.186 & 0.037 \\
\hline 13 & I get very tense hearing stories about deliveries & 0.788 & & \\
\hline 14 & $\begin{array}{l}\text { I am concerned that the physical discomforts of } \\
\text { pregnancy might persist after childbirth }\end{array}$ & 0.714 & 0.068 & 0.156 & 0.009 \\
\hline 15 & I can really share my feelings with my partner & 0.024 & 0.762 & \\
\hline 16 & I worry about gaining too much weight & 0.321 & 0.147 & 0.502 & \\
\hline & & & & & \\
\hline
\end{tabular}




\section{Confirmatory factor analysis}

Since the fit indices in the theoretical model (NNFI $>0.9, \mathrm{CFI}>0.9, \mathrm{NFI}>0.9, \mathrm{IFI}>0.9$, and RMSEA $<0.08)$ achieved acceptable values, the translated questionnaire exhibited appropriate fitness in terms of confirmatory factor analysis (Table 4 and Figure 2).

Table 4. Confirmatory factor analysis results of the TPDS-P

\begin{tabular}{|lll|}
\hline Index & Desirable score & Obtained score \\
\hline Chi-square statistic & $\mathrm{p}<0.05$ & $<0.001$ \\
\hline Comparative fit index (CFI) & $>0.9$ & 0.927 \\
\hline Normal fit index (NFI) & $>0.9$ & 0.937 \\
\hline Tucker-Lewis index (TLI or NNFI) & $>0.9$ & 0.941 \\
\hline Incremental fit index (IFI) & $>0.9$ & 0.989 \\
\hline
\end{tabular}

Table 5 shows the correlation coefficient between the subscales of TPDS-P and DASS-21. There is poor to moderate but significant direct correlation between the subscales of the two questionnaires.

Table 5. Criterion validity between TPDS-P and DASS-21

\begin{tabular}{|c|c|c|c|c|}
\hline \multirow[t]{3}{*}{ DASS-21 } & \multicolumn{4}{|c|}{ TPDS-P } \\
\hline & \multicolumn{2}{|c|}{ Negative affect } & \multicolumn{2}{|c|}{ Partner involvement } \\
\hline & $\mathbf{r}$ & (p) & $\mathbf{r}$ & (p) \\
\hline Anxiety & 0.562 & $(0.001)$ & 0.317 & $(0.001)$ \\
\hline Depression & 0.322 & $(0.001)$ & 0.296 & $(0.001)$ \\
\hline Stress & 0.560 & $(0.001)$ & 0.462 & $(0.001)$ \\
\hline
\end{tabular}

Cronbach's alpha coefficient calculated for the TPDS-P and the Test-retest results are shown in Table 6. ICC was 0.81 .

Table 6. Cronbach's alpha coefficient and Test-retest results for the TPDS-P 


\begin{tabular}{|lll|}
\hline Variable & $\begin{array}{l}\text { Cronbach's alpha } \\
\text { coefficient }\end{array}$ & $\begin{array}{l}\text { Test-retest } \\
\text { coefficient } \\
\mathbf{r}(\mathbf{p})\end{array}$ \\
\hline $\begin{array}{l}\text { Tilburg Pregnancy Distress Scale-Persian } \\
\text { Version }\end{array}$ & 0.810 & - \\
\hline partner involvement subscale & 0.866 & $0.748(0.021)$ \\
\hline negative affect subscale & 0.854 & $0.622(0.001)$ \\
\hline
\end{tabular}

\section{Discussion}

In the present study, KMO was $0.846(p=0.001)$, which is higher than the original questionnaire (Victor J. M. Pop et al.'s research). The values obtained for the TPDS-P were in line with those for the original one in terms of sample size and degree of freedom (14).

In the analysis of the TPDS-P, the total variance explained by the two factors was 51.42 percent, which is higher than that of the study conducted by Ertugrul et al. in Turkey in 2015 and that of the original questionnaire (1). The obtained variance usually lies between 40 and 60 percent in sociological studies (15). In one-factor scales, an obtained variance above 30 percent is sufficient, but it seems to need to be higher in multi-factor scales (16).

In the present study, in some items, the results of factor loading and rate of answering were different from the results of the original questionnaire studies. None of the items had exhibited a factor loading lower than 0.30 in the original questionnaire (1), but in this research, item 7 (i.e., "I worry about my job once the baby is born") had rarely been answered, which may be because 78.1 percent of the pregnant women in our study were housewives with no additional jobs, so they had thought there was no need to respond to this item. That is why Pop has suggested that this item should be removed from the questionnaire, or that the pregnant women should be advised to consider their occupation as housewives as a job in order to answer that item (1).

Eleventh item of the questionnaire (i.e., "I often worry about choices concerning the delivery") is not very debatable in Iranian society, where patients mostly trust their physicians, who decide on the type of delivery (17). That is why the factor loading related to anxiety was low for this item. Cronbach's alpha coefficient was 0.81 in the presence of this item, which was obtained as 0.75 upon its removal. Moreover, most of the pregnant women under investigation (57.8 percent) had experienced more than two childbirths, and seemed to be well informed on the types of delivery; therefore, little distress had been expressed.

There was considerable distress about Item 16 (i.e., "I worry about gaining too much weight") in our population under investigation, with a factor loading higher than 0.30 . Iranian women seem to have some distress about gaining weight after pregnancy and issues concerning beauty. Unlike our research, this 
item had exhibited no effect in the population under investigation in a study on TPDS conducted in Turkey, where a factor loading of less than 0.30 had been reported. Based on a review of relevant resources, it seems to be suggested by a governing thought in the Turkish culture that the more weight a mother gains during pregnancy; the healthier the baby is born by her (17). Moreover, most of the pregnant women in our research (74.4 percent) held high school education, diploma or academic degrees. They seem to have been better informed on healthy pregnancy and doing sports during the period; hence, they had greater sensitivity to gaining weight during pregnancy. Upon removal of this item, Cronbach's alpha was obtained as 0.70 .

In the present study, the result of the correlation coefficient test between the subscales of TPDS-P and DASS-21 was not strong and was poor to moderate, but it was significant nonetheless, and it seems that if the psychiatric interview and examination were performed, perhaps better results would be obtained in the criterion validity.

The overall Cronbach's alpha coefficient was calculated to be 0.81 for TPDS-P, having been 0.78 in the original scale and 0.70 in Turkish version of scale (1), which demonstrates that this scale is suitable to be used in the Iranian culture and Persian language. Moreover, Cronbach's alpha was obtained to be higher for the examined subscales than the overall coefficient. It was obtained as 0.86 for the partner involvement subscale and as 0.85 for the negative affect subscale, indicating that the scale performs even better in regard to the items that investigate the partner involvement aspects of pregnancy distress.

As for the confirmatory factor analysis, the indices in the analysis of 4 items in the partner involvement subscale were inappropriate, and item 1 (i.e., "I am enjoying my pregnancy") exhibited a very low factor loading. Given the results obtained from exploratory factor analysis and the higher factor loading of this item under the second (i.e., partner involvement) factor, factor analysis was made again to include 5 items under the partner involvement factor; therefore, both the factor loading of item 1 and the overall results of confirmatory factor analysis were thus corrected. Therefore, the partner involvement factor contains 5 items, and the negative affect factor contains 11 items in the Persian version of TPDS.

\section{Conclusion}

It can be concluded that Tilburg Pregnancy Distress Scale-Persian version (TPDS-P) as a scale with appropriate validity and reliability can be utilized in the Iranian society for the assessment of the distress among pregnant women.

\section{Recommendations and limitations of the study}

Since most of the pregnant women under investigation in the present study were housewives with no additional job, it is suggested that as many women with other jobs as housewives be included in future studies, so that the scale can be assessed for them as well. 
Since the present study was conducted at urban health centers, it is suggested that similar researches be performed on a rural population.

\section{List Of Abbreviations}

TPDS-P: Tilburg Pregnancy Distress Scale-Persian Version

DASS-21: Depression Anxiety Stress Scale-21

SPSS: Statistical Package for the Social Sciences

ICC: Intra-class Correlation Coefficient

KMO: Kaiser-Meyer-Olkin

RMSEA: Root Mean Square Error of Approximation

CFI: Comparative Fit Index

NFI: Normal Fit Index

TLI: Tucker-Lewis Index

NNFI: Non Normed Fit Index

IFI: Incremental Fit Index

\section{Declarations}

\section{Ethics approval and consent to participate}

Conducting this study was approved by the ethical committee board at Tabriz University of Medical Sciences. The approval code is IR.TBZMED.REC.1396.70.

\section{Consent for publication}

Not applicable

\section{Availability of data and materials}

All the data and materials will be available from the corresponding author upon any reasonable request.

\section{Competing interests}

The authors declare that they have no competing interests. 


\section{Funding}

Conducting this study was supported and funded by Tabriz University of Medical Sciences. The grant number is: $5 / d / 575113$.

\section{Authors' contributions}

All authors approved the study. SP and FR conceived the study. SP and SV collected the data. All authors analyzed the data, interpreted the findings and contributed to the validation study of the research questionnaire. SP wrote the first draft of the manuscript. All authors read and critically revised the first draft and confirmed the final version of the manuscript.

\section{Acknowledgments}

We would like to extend our sincere gratitude to all participants (pregnant women) for their invaluable participation in this study. Without their participation, the study could not have been completed.

\section{References}

1. Ertuğrul $M$, Okumuş $H$, Aluş Tokat $M$, Bektaş $M$. Psychometric evaluation of the Tilburg pregnancy distress scale-Turkish version (TPDS-T). Journal of Transcultural Nursing. 2015 Nov;26(5):499-506.

2. Kent A. Psychiatric disorders in pregnancy. Obstetrics, Gynaecology \& Reproductive Medicine. 2011 Nov 1;21(11):317-22.

3. Alder J, Fink N, Bitzer J, Hösli I, Holzgreve W. Depression and anxiety during pregnancy: a risk factor for obstetric, fetal and neonatal outcome? A critical review of the literature. The Journal of MaternalFetal \& Neonatal Medicine. 2007 Jan 1;20(3):189-209.

4. Antony MM, Bieling PJ, Cox BJ, Enns MW, Swinson RP. Psychometric properties of the 42-item and 21-item versions of the Depression Anxiety Stress Scales in clinical groups and a community sample. Psychological assessment. 1998 Jun;10(2):176.

5. Pop VJ, Pommer AM, Pop-Purceleanu M, Wijnen HA, Bergink V, Pouwer F. Development of the Tilburg pregnancy distress scale: the TPDS. BMC pregnancy and childbirth. 2011 Dec;11(1):1-8.

6. Beijers R, Jansen J, Riksen-Walraven M, de Weerth C. Maternal prenatal anxiety and stress predict infant illnesses and health complaints. Pediatrics. 2010 Aug 1;126(2):e401-9..

7. Wenzel A, Stuart SC. Anxiety in childbearing women: Diagnosis and treatment. American Psychological Association; 2011.

8. Lancaster CA, Gold KJ, Flynn HA, Yoo H, Marcus SM, Davis MM. Risk factors for depressive symptoms during pregnancy: a systematic review. American journal of obstetrics and gynecology. 2010 Jan 1;202(1):5-14.

9. Asghari A, Saed F, Dibajnia P. Psychometric properties of the Depression Anxiety Stress Scales-21 (DASS-21) in a non-clinical Iranian sample. Int J Psychol. 2008;2(2):82-102. 
10. Kellar SP, Kelvin EA. Munro's statistical methods for health care research. Wolters Kluwer Health/Lippincott Williams \& Wilkins;; 2013.

11. Moghaddam A, Saed F, Dibajnia P, Zangeneh J. A preliminary validation of the depression, anxiety and stress scales (DASS) in non-clinical sample. Scientific Journal of Clinical Psychology \& Personality. 2008 Nov 10;1(31):23-38.

12. Yıldırım A, Boysan M, Kefeli MC. Psychometric properties of the Turkish version of the Depression Anxiety Stress Scale-21 (DASS-21). British Journal of Guidance \& Counselling. 2018 Sep 3;46(5):58295.

13. Munro BH. Statistical methods for health care research. lippincott williams \& wilkins; 2005.

14. Polit DF, Beck CT. Essentials of nursing research: Appraising evidence for nursing practice. Lippincott Williams \& Wilkins; 2009.

15. Aypay A. Elementary School Student Burnout Scale for Grades 6-8: A Study of Validity and Reliability. Educational Sciences: Theory and Practice. 2011;11(2):520-7.

16. Sezer A. Sağlık okuryazarlığının sağlıklı yaşam biçimi davranışları ile ilişkisi. Journal of Anatolia Nursing and Health Sciences. 2012.17(3), 33-41.

17. MOHAMMAD BA, TABATABAEI S, MOHAMMAD SN, Yazdani M. Factors influencing cesarean delivery method in Shiraz hospitals.2009, 37-45.

\section{Figures}




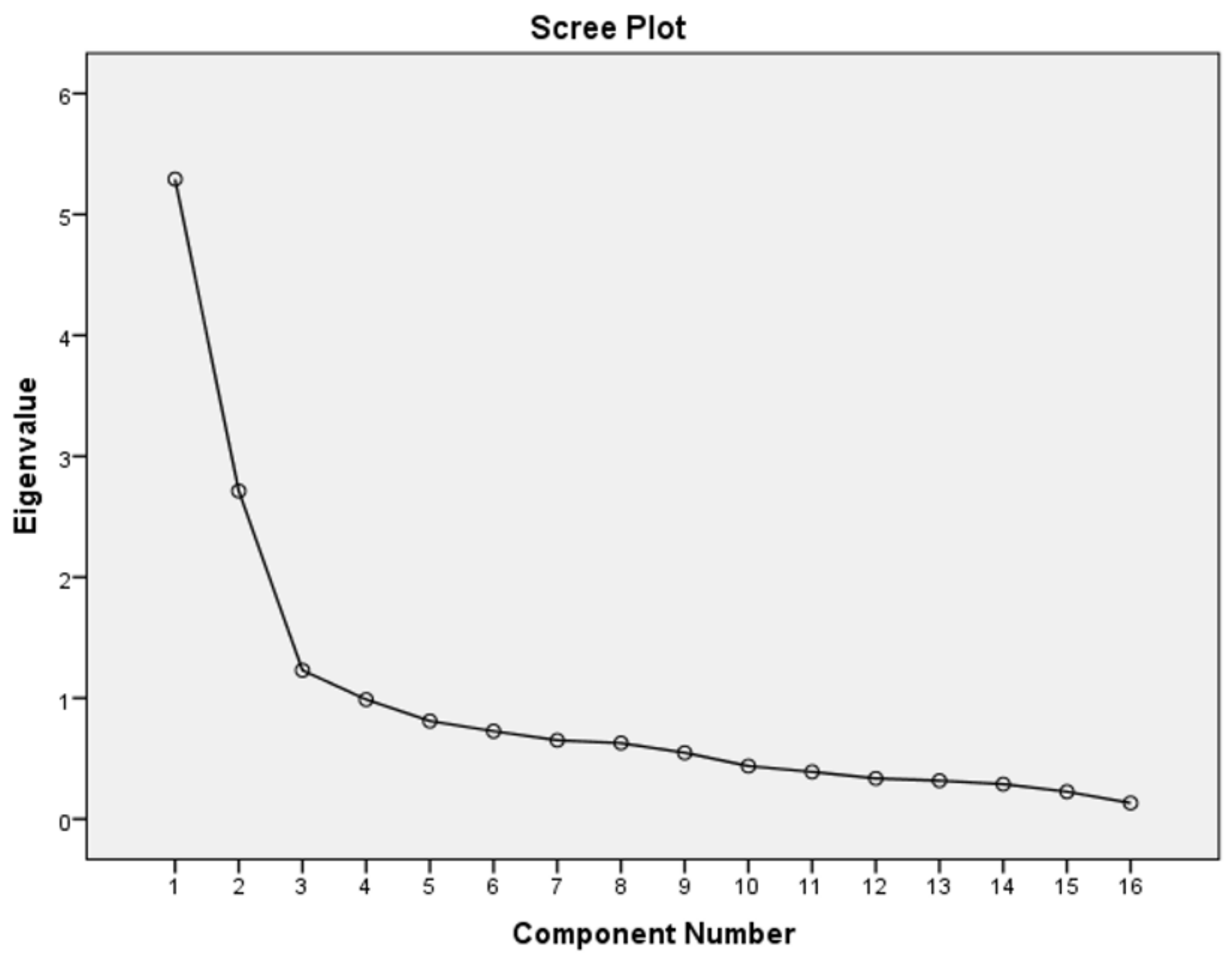

Figure 1

Factor load scree plot of the items for determining the number of extracted factors of the TPDS-P 


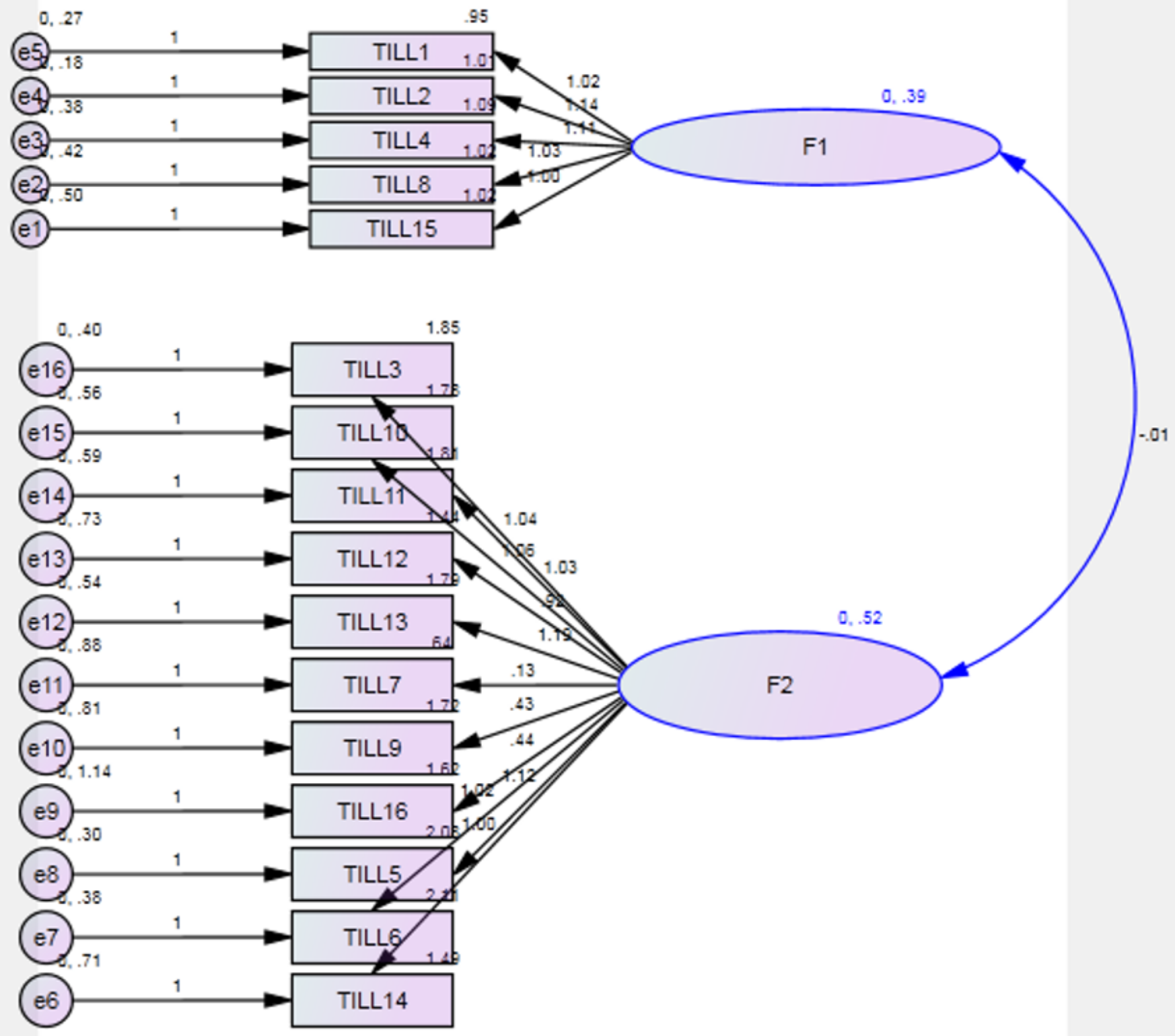

Figure 2

Confirmatory factor analysis graph of the TPDS-P F1: partner involvement F2: negative affect 